\title{
MESO-SCALE MODELING OF IRRADIATION IN PRESSURIZED WATER REACTOR CONCRETE BIOLOGICAL SHIELDS
}

\author{
ALAIN GIORLA*, YANN LE PAPE* AND HAI HUANG ${ }^{\dagger}$ \\ * Oak Ridge National Laboratory \\ Oak Ridge, TN USA \\ e-mail: giorlaab@ornl.gov \\ ${ }^{\dagger}$ Idaho National Laboratory \\ Idaho Falls, ID USA
}

Key words: Creep-damage, Irradiation, Meso-scale Modeling

\begin{abstract}
Neutron irradiation exposure causes aggregate expansion, namely radiation-induced volumetric expansion (RIVE). The structural significance of RIVE on a portion of a prototypical pressurized water reactor (PWR) concrete biological shield (CBS) is investigated by using a mesoscale nonlinear concrete model with inputs from an irradiation transport code and a coupled moisture transport-heat transfer code. RIVE-induced severe cracking onset appears to be triggered by the initial shrinkage-induced cracking and propagates to a depth of $>10 \mathrm{~cm}$ at extended operation of 80 years. Relaxation of the cement paste stresses results in delaying the crack propagation by about 10 years.
\end{abstract}

\section{INTRODUCTION}

Neutron irradiation has been identified as a potential concrete degradation phenomenon for the long-term operation of nuclear power plant (NPP) in the United States, inducing a very high expansion of the material as well as loss of mechanical properties for neutron fluences above $\approx 10^{19} \mathrm{n} \cdot \mathrm{cm}^{-2}$ [1,2]. The main concrete structure exposed to neutron irradiation in a light water reactor (LWR) is the CBS which contains the reactor pressure vessel. These structures are exposed to strong gradients of internal humidity and neutron flux, which raise the question of the depth and extent of the radiation-induced degradation through the CBS.

Pomaro et al. [3] found that damage was limited to the surface layer exposed to irradiation, and was mostly due to the loss of mechanical properties that was prescribed by the model as a function of the neutron fluence. However, their model did not account for the RIVE, which may cause additional mechanical damage due to (1) the differential expansion between the aggregates and the cement paste, and, (2) the effects of structural restraints induced by the geometry of the CBS. Le Pape [4] showed with a simplified one-dimensional axisymmetric model that RIVE strong gradient lead to excessive biaxial compression elastic stresses near the reactor cavity and hoop tensile stresses toward the back of the CBS.

In the present study, we investigate the temperature, moisture and neutron flux gradients effects in a CBS using a meso-scale model previously developed and validated [5] on irradiated concrete data obtained in test reactors. This model accounts for the effects of RIVE in the aggregates as well as damage and visco-elastic stress relaxation in the cement paste. These 
simulations are based on 80 years of operation to estimate the potential degradation induced during long-term operations of commercial NPPs.

\section{NUMERICAL MODEL}

The model assumes uncoupling between the transport and mechanical properties of the material. Therefore, the irradiation, temperature, and moisture simulations are carried out separately, and their output are used as input for the mechanical model. Literature suggests that gamma irradiation have limited effects on the mechanical properties of cement paste and concrete [6], and unclear consequences of creep and shrinkage [7]. Hence, gamma irradiation is neglected in this study.

Transport and structural simulations were carried out with different tools, in the following order:

\subsection{Irradiation}

The neutron and gamma irradiation fields were obtained with the DORT computer based on 80 years of operation of a Westinghouse design 3-loop PWR [2,8]. The temperature profile is calculated accounting for the heat deposition generated by gamma and neutron irradiation. The resulting irradiation and temperature profiles are the same as the profiles used by Le Pape [4]. For these calculations, the concrete is assumed homogeneous, and the temperature constant over time (steady-state regime).

\subsection{Moisture Transport}

The moisture profile is computed with a coupled model first presented by Bažant et al in [9]. The temperature field was taken as an input, using the result of the previous simulation. The model was implemented in the MOOSE finite element framework [10,11], and assumed that the concrete was an homogeneous material. The time-dependent moisture profile evolution is illustrated in Figure 1 .

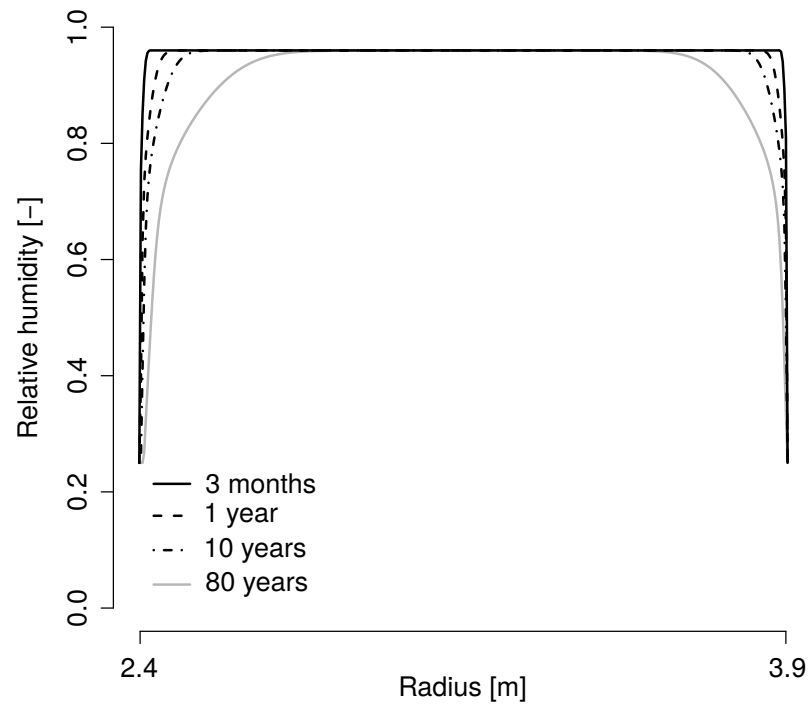

Figure 1: Relative humidity profile across the CBS at different time.

Because of the very low relative humidity of the air inside the containment building, the concrete surface layer creates a moisture transport buffer resulting in leaving the inner section of the wall near saturation, even after 80 years of operation. This result is consistent with monitoring data from actual NPPs in Sweden [12].

\subsection{Structural Analysis}

The mechanical simulation are carried out in the finite element framework AMIE [13, 14]. The model consists in a portion of a twodimensional vertical section of the CBS (see Figure 2) assuming plane strain conditions.

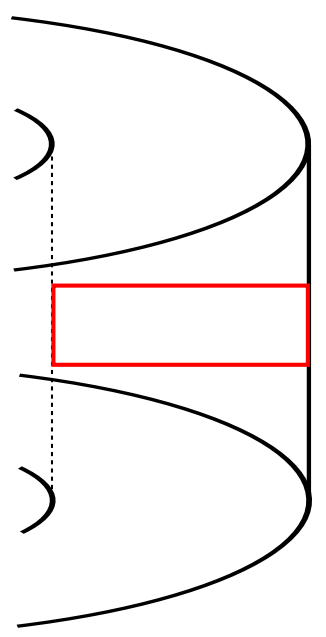

Figure 2: Vertical slice of the CBS. Dimensions not to scale. 
The CBS wall is divided in two portions: (1) An 'inner' portion, oriented toward the reactor cavity where irradiation-induced damage is expected to occur, and hence, including an explicit representation of aggregates and mortar (meso-scale model), and, (2) an 'outer' portion, providing accurate structural stiffness, where concrete is modeled as an homogeneous continuum to limit the computation time. Aggregates geometries are idealized as disks, with diameters distributed between $2 \mathrm{~cm}$ and $5 \mathrm{~mm}$ according to a Füller distribution [15]. The surface fraction of the aggregates in the 'inner' portion is equal to $35 \%$. The mechanical properties of the matrix are increased to account for the missing fraction of fine aggregates.

The mesh is refined in the inner portion, and, is gradually coarsened towards CBS backwall (see Figure 3). The mesh consists in $\approx$ 32,000 triangular elements conforming to the aggregates geometry.

The vertical displacements of the top and bottom edges of the sample are blocked to represent structural restraint imposed by upper and lower portions of the CBS. The right edge is blocked in the horizontal direction to prevent instability.

The mesh, microstructure and boundary conditions are shown in Figure 3.
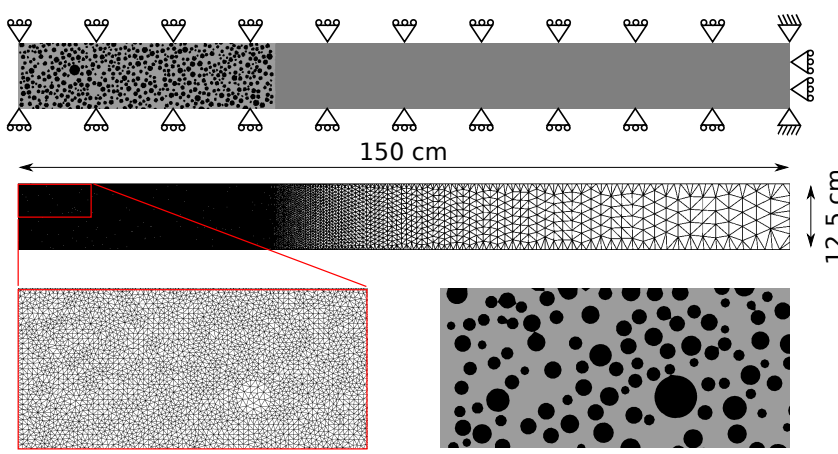

Figure 3: Microstructure and boundary conditions (top) and mesh (middle) of the slice; Details of the mesh (bottom-left) and the microstructure (bottom-right) in the inner region.
Each simulation requires approximately 48 hours computation time on a dedicated workstation.

\section{CONSTITUTIVE BEHAVIOR}

The mechanical model was first presented in [5] and is briefly summarized below.

\subsection{Mortar}

The mortar paste is considered as a viscoelastic quasi-brittle material. The visco-elastic behavior is decomposed into a short-term recoverable deformation, and a long-term irrecoverable deformation that increases logarithmically with time. High temperature accelerates creep with an Arrhenius-type law, while low relative humidity decreases its amplitude. Damage is characterized with a linear softening postpeak behavior and computed with a non-local creep-damage algorithm [16]. The mortar is assumed to fail exclusively in tension at the mesoscale level, as failure due to macroscopic compression in concrete is caused local tension in the cement paste. Finally, the mortar is subject to both thermal expansion and drying shrinkage

\subsection{Aggregates}

The aggregates are considered elastic with thermal- and radiation-induced volumetric expansions. The RIVE follows the empirical sigmoid curve proposed by Zubov and Ivanov [17]:

$$
\varepsilon_{\mathrm{RIVE}}(\Phi)=\kappa \varepsilon_{\max } \frac{e^{\delta \Phi}-1}{\varepsilon_{\max }+\kappa e^{\delta \Phi}}
$$

The aggregates are represented with homogeneous disks. Interfacial transition zone is not accounted for. Failure in the aggregates is not considered as mortar reaches its tensile or compressive strength first.

\subsection{Material Properties}

The aggregate elastic and thermal properties correspond to typical values for ordinary structural concrete used for NPP construction. The mortar elastic, visco-elastic and damage properties are calibrated so that the simulated concrete exhibits the same macroscopic properties 
as used by Le Pape in [4]. The Young's modulus of the numerical sample is $34 \mathrm{GPa}$, and its compressive strength $40 \mathrm{MPa}$. The parameters for the aggregate RIVE were calibrated by Le Pape based on a statistical analysis of data from the literature [2, 4]. Other parameters (such as the creep and shrinkage properties) were taken from the literature for typical normal-weight concrete. The material properties used in the mechanical simulation are tabulated in Table 1

Table 1: Material Properties. ${ }^{(1)}$ Calibrated to obtain a concrete with a Young's modulus of $34 \mathrm{GPa}$ and compressive strength $40 \mathrm{MPa}$. (2) Typical value for concrete. (3) Calibrated on Le Roy's creep experiments on cement paste [18]. (4) Calibrated on Wittmann's creep experiments on cement paste at different relative humidities [19]. ${ }^{(5)}$ Taken from the model of Le Pape [4]

\begin{tabular}{llrll}
\hline Cement paste & & & & \\
Elasticity & $\mathrm{E}_{\mathrm{p}}$ & 26 & {$[\mathrm{GPa}]$} & $(1)$ \\
& $\nu_{p}$ & 0.2 & {$[-]$} & $(2)$ \\
Creep & $\eta_{c}$ & 40 & {$[\mathrm{GPa} . \mathrm{d}]$} & $(3)$ \\
& $\tau_{c}$ & 2 & {$[\mathrm{~d}]$} & $(3)$ \\
& $E_{a c t}$ & 5000 & {$[\mathrm{~K}]$} & $(2)$ \\
& $h_{0}$ & 0.2 & {$[-]$} & $(4)$ \\
Failure & $\epsilon_{t}$ & 0.5 & {$[\mathrm{~mm} / \mathrm{m}]$} & $(1)$ \\
& $\epsilon_{y, t}$ & 1.0 & {$[\mathrm{~mm} / \mathrm{m}]$} & $(1)$ \\
Thermal Exp. & $\alpha_{p}$ & 9 & {$\left[10^{-6} 1 / \mathrm{K}\right]$} & $(2)$ \\
Drying Shr. & $\alpha_{s h}$ & 1 & {$[\mathrm{~mm} / \mathrm{m} 1 / \mathrm{RH}]$} & $(2)$ \\
\hline Aggregates & & & & \\
Elasticity & $\mathrm{E}_{a}$ & 60 & {$[\mathrm{GPa}]$} & $(2)$ \\
& $\nu_{a}$ & 0.2 & {$[-]$} & $(2)$ \\
Thermal Exp. & $\alpha_{a}$ & 7.5 & {$\left[10^{-6} 1 / \mathrm{K}\right]$} & $(2)$ \\
RIVE & $\varepsilon_{\max }$ & 9.36 & {$[\mathrm{~mm} / \mathrm{m}]$} & $(5)$ \\
& $\kappa$ & 9.68 & {$[\mathrm{~mm} / \mathrm{m}]$} & $(5)$ \\
& $\delta$ & 0.3092 & {$\left[10^{-19} \mathrm{~cm}^{2} / \mathrm{n}\right]$} & $(5)$ \\
\hline
\end{tabular}

\section{RESULTS AND DISCUSSION}

A scenario matrix of 9 cases is investigated, corresponding to three different mechanical models increasing in complexity, crossed with three different exposure conditions. The mechanical models alternate among the following mortar behaviors: (1) pure elasticity, (2) quasibrittle elasticity, and, (3) coupled damage-creep constitutive model While the exposure conditions vary from: (1) irradiation at constant relative humidity (96\%), to (2) irradiation and drying simultaneously, and, finally to (3) drying only (reference case).

Varying the exposure conditions and mechanical models make possible the identification of the predominant phenomena for the evaluation of the structural significance of irradiated concrete.

\subsection{Damage Development}

Drying without irradiation results in the formation of non-percolating micro-cracking localized on the skin of the CBS. Irradiationinduced damage patterns are similar irrespectively of creep: Vertical cracks form in the vicinity of the reactor cavity, evidently resulting from the constrained vertical deformation. The maximum damaged depth, defined as the maximum distance between the inner surface of the CBS and the farthest damaged element along the horizontal axis, was about $11 \mathrm{~cm}$ at 80 years of operation. An example of damage pattern (obtained for the creep-damage model with both irradiation and variable relative humidity) is shown in Figure 4. The outer surface does not suffer from any damage, despite being subject to relatively high tensile stress.

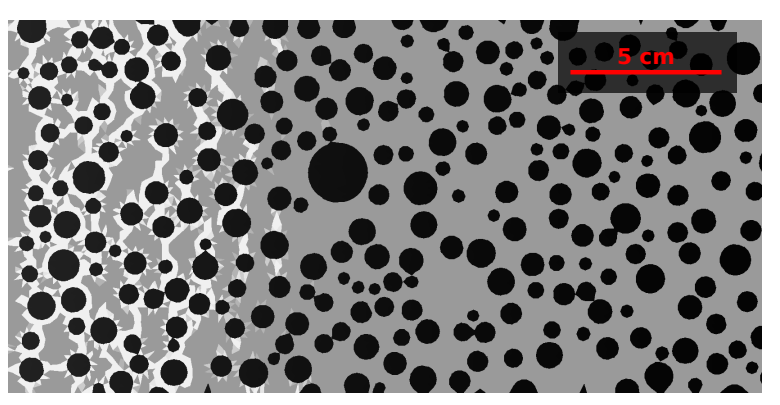

Figure 4: Damage pattern obtained after 80 years of irradiation under variable relative humidity with the creepdamage model. Black: aggregate; gray: sound mortar; white: cracked elements. 


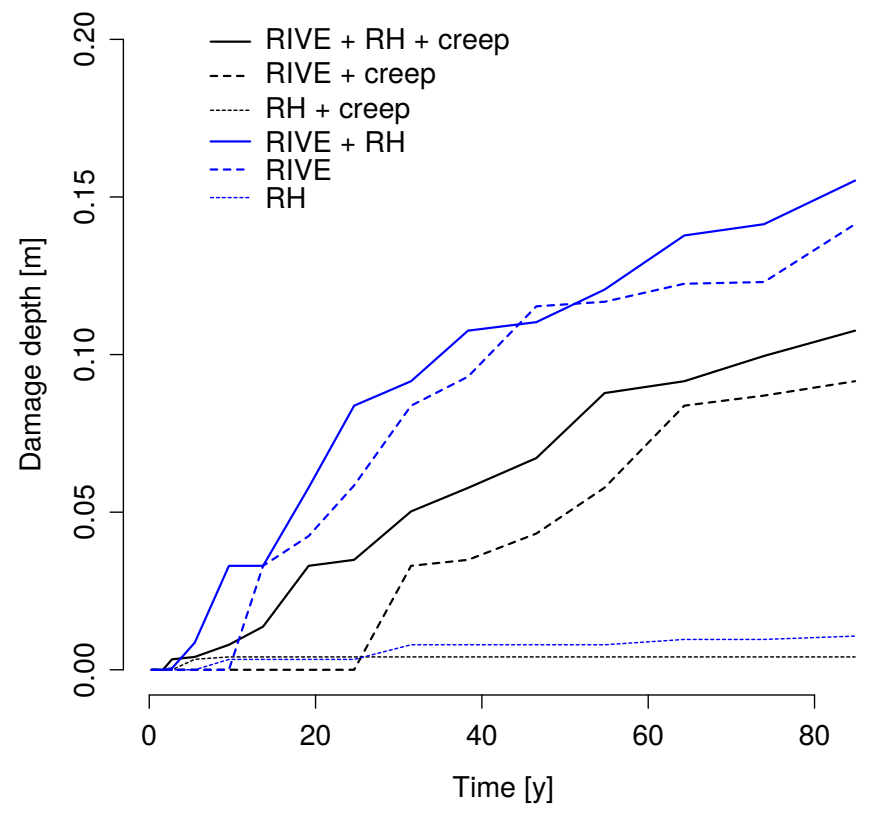

Figure 5: Damage depth as a function of time for different environmental conditions.

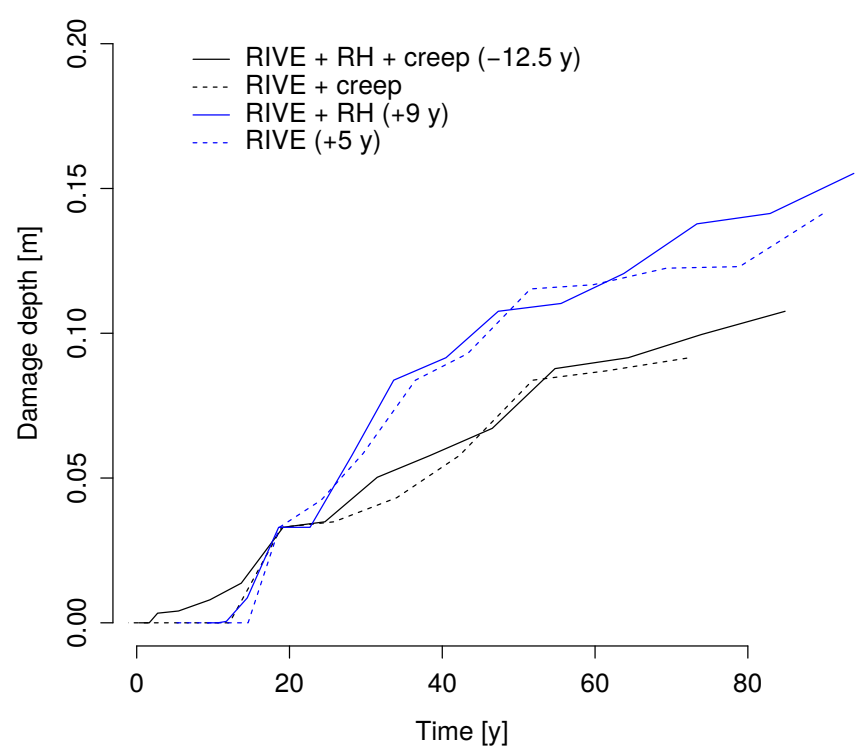

Figure 6: Damage depth as a function of time for different environmental conditions, shifted.

The evolution of the damage depth through the wall is plotted as a function of time in Figure 5. While drying alone produces very limited damage, it clearly triggers earlier the development of RIVE-induced damage, but does not appear to affect the subsequent damage propagation kinetics toward the depth of the CBS, as shown in Figure 6, in which all curves have been shifted so that the damage initiations coincide.

This shows that the evolution of relative humidity in the NPP must be accounted for in order to predict the instant at which damage initiates, while creep is a dominant factor in both the initiation and the later propagation stage.

\subsection{Comparison with elastic simulations}

While meso-scale simulations provide very detailed information at the material characteristic scale, it generally cannot be used in the context of structural analysis for full-size civil engineering applications. Design and structural performance evaluations rely on preliminary elastic calculations, and require non-linear and/or time-dependent simulations, only if these first results indicate a possible structural deficiency. Therefore, this section explore whether a purely elastic model can provide a first approximation for the damage caused by irradiation.

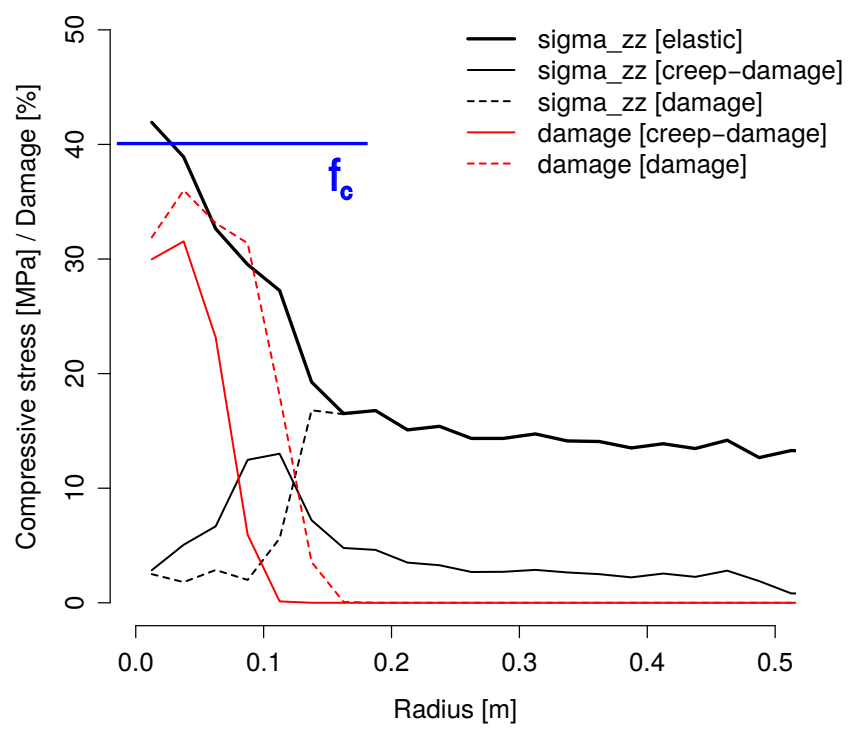

Figure 7: Average compressive vertical stress (in black) and damage (in red) accross the CBS for the three mechanical models (elastic, damage, creep-damage) at 80 years, accounting for both RIVE and variable relative humidity. The blue line indicates the concrete compressive strength (40 MPa).

However, direct comparison with an homogenized model (such has presented by Le Pape in [4]) is not directly possible, due to the geometrical assumptions used in the present simu- 
lations. Indeed, the sample simulated here does not account for axi-symmetry of the CBS, and the hoop strains and stresses were neglected. A more fitting comparison would be possible by using a radial slice of the wall instead of a vertical slice, as the vertical stresses do not seem to play a significant role in the damage propagation shown here.

Figure 7 shows the average vertical stress, $\sigma_{z z}(r)$, profiles in concrete across the CBS at 80 years for the three mechanical models, alongside the average damage obtained with and without accounting for creep.

The purely elastic simulation results in finding that only a thin surface layer of $\approx 1 \mathrm{~cm}$ is subjected to stresses exceeding the concrete compressive strength (40 MPa), whereas, the actual damage depth calculated when mortar behaves like a quasi-brittle material in tension, reaches about $10-12 \mathrm{~cm}$. This result provides some indication that the stress level in concrete is not an accurate indicator of the potential irradiation-induced damage occurrence. A macroscopic model for irradiated concrete structures should therefore take into account the localization of stresses in the microstructure, for example, using a backward analytic homogenization scheme to extract the average stress inside the cement paste.

\section{CONCLUSIONS}

Irradiation-induced damage in a prototypical PWR CBS is quantitatively estimated with a meso-scale nonlinear concrete model using inputs from an irradiation transport code and a coupled moisture transport-heat transfer code. Although the model cannot be extended to capture the structural complexity of a full-3D CBS and the azimuthal and vertical variations of the neutron flux, it provides insightful information of the damage propagation at the reactor beltline, i.e., at the highest irradiation flux, during extended operation beyond 60 years. At 80 years, the damage front reaches about $11 \mathrm{~cm}$ from the concrete surface facing the reactor pressure vessel. Due to the important volume expansion of aggregate under neutron irradia- tion, the damage in this zone is particularly severe. The structural significance of irradiationinduced damage preceding an hypothetical accidental scenario reamins to be evaluated.

\section{ACKNOWLEDGEMENTS}

This research is sponsored by the U.S. Department of Energy (DOE) Light Water Reactor Sustainability Program. This manuscript has been authored by UT-Battelle, LLC under Contract No. DE-AC05-00OR22725 with the U.S. Department of Energy. The United States Government retains and the publisher, by accepting the article for publication, acknowledges that the United States Government retains a non-exclusive, paid-up, irrevocable, world-wide license to publish or reproduce the published form of this manuscript, or allow others to do so, for United States Government purposes. The Department of Energy will provide public access to these results of federally sponsored research in accordance with the DOE Public Access Plan (http://energy.gov/downloads/ doe-public-access-plan).

\section{REFERENCES}

[1] H. Graves, Y. Le Pape, D. Naus, J. Rashid, V. Saouma, A. Sheikh, and J. Wall. Expanded material degradation assessment (EMDA), volume 4: Aging of concrete. Technical Report NUREG/CR7153, ORNL/TM-2011/545, U.S. Nuclear Regulatory Commission, 2014.

[2] K.G. Field, I. Remec, and Y. Le Pape. Radiation Effects on Concrete for $\mathrm{Nu}$ clear Power Plants, Part I: Quantification of Radiation Exposure and Radiation Effects. Nuclear Engineering and Design, 282:126-143, 2015.

[3] B. Pomaro, V.A. Salomoni, F. Gramegna, G. Prete, and C.E. Majorana. Radiation damage evaluation on concrete within a facility for selective production of exotic species (SPES Project), Italy. Journal 
of Hazardous Materials, 194(0):169-177, 2011.

[4] Y. Le Pape. Structural effects of radiationinduced volumetric expansion on unreinforced concrete biological shields. $\mathrm{Nu}$ clear Engineering and Design, 295:534548, 2015.

[5] A. Giorla, M. Vaitová, Y. Le Pape, and P. Štemberk. Meso-scale modeling of irradiated concrete in test reactor. $\mathrm{Nu}$ clear Engineering and Design, 295:5973, 2015.

[6] B.S. Gray. The effects of reactor radiation on cement and concrete. In Proceedings of an Information Exchange Meeting on 'Results of Concrete Irradiation Programmes', volume EUR 4751 f-e, Brussels, Belgium, April 19 1971. Commission des Communautés Européennes.

[7] D.C. McDowall. The effects of gamma radiation on the creep properties of concrete. In Proceedings of an Information Exchange Meeting on 'Results of Concrete Irradiation Programmes', volume EUR $4751 \mathrm{f}$-e, pages 55-69, Brussels, Belgium, April 19 1971. Commission des Communautés Européennes.

[8] I. Remec, T.M. Rosseel, K.G. Field, and Y. Le Pape. Characterization of radiation fields in biological shields of NPPs for assessing concrete degradation. In Proceedings of the Fifteenth International Symposium on Reactor Dosimetry, Aixen-Provence, France, May 18-23 2014.

[9] Z.P. Bažant, J.-C. Chern, and W. Thonguthai. Finite element program for moisture and heat transfer in heated concrete. Nuclear Engineering and Design, 68(1):61-70, 1982.

[10] D. Gaston, C. Newman, G. Hansen, and D. Lebrun-Grandie. Moose: A parallel computational framework for coupled systems of nonlinear equations. Nuclear Engineering and Design, 239(10):17681778, 2009.

[11] H. Huang, B. Spencer, and G. Cai. Grizzly model of multi-species reactive diffusion, moisture/heat transfer, and alkalisilica reaction in concrete. Technical Report INL/EXT-15-36425, Idaho National Laboratory, September 2015.

[12] M. Oxfall. Climatic conditions inside nuclear reactor containment, monitoring campaign. Technical Report TVBM-13/3172, Lund University, Lund University, Faculty of Engineering, Division of Building Materials P.O. Box 118 SE-221 00 Lund, Sweden www.byggnadsmaterial.lth.se, 2013.

[13] C.F. Dunant and K.L. Scrivener. Micromechanical modelling of alkali-silicareaction-induced degradation using the amie framework. Cement and Concrete Research, 40(4):517-525, 2010.

[14] A.B. Giorla, K.L. Scrivener, and C.F. Dunant. Finite elements in space and time for the analysis of generalised viscoelastic materials. International Journal for Numerical Methods in Engineering, 97(6):454-472, 2014.

[15] William B Fuller and Sanford E Thompson. The laws of proportioning concrete. Transactions of the American Society of Civil Engineers, 59(2):67-143, 1907.

[16] A. Giorla, Y. Le Pape, and C. Dunant. Computing creep-damage interactions in irradiated concrete. Journal of Nanomechanics and Micromechanics, 2016. submitted.

[17] V.G. Zubov and A.T. Ivanov. Expansion of quartz caused by irradiation with fast neutrons. Soviet Physics Crystallography, 11(3):372-374, 1966. 
[18] R. Le Roy. Déformations instantanées et différées des bétons à hautes performances. PhD thesis, Ecole Nationale des Ponts et Chaussées, 1995.
[19] F.H. Wittmann. Einfluß des Feuchtigkeitsgehaltes auf das Kriechen des Zementsteines. Rheologica Acta, 9(2):282287, 1970. 